\title{
A Simulation Study of Kelvin Waves Interacting with Synoptic Events during December 2016 in the South China Sea and Maritime Continent
}

\author{
LI-HUAN HSU \\ National Science and Technology Center for Disaster Reduction, New Taipei City, Taiwan \\ LI-SHAN TSENG \\ Department of Earth Sciences, National Taiwan Normal University, Taipei, Taiwan \\ Shu-Yu Hou, Buo-Fu Chen, And CHung-Hsiung SuI \\ Department of Atmospheric Sciences, National Taiwan University, Taipei, Taiwan
}

(Manuscript received 23 February 2020, in final form 28 April 2020)

\begin{abstract}
This study evaluates the model simulation of interaction between convectively coupled tropical disturbances in the South China Sea (SCS) and Maritime Continent (MC). The Model for Prediction Across Scales (MPAS) is used to simulate the major interaction events in December 2016 with a fixed 60-km horizontal resolution and a variable $60-15-\mathrm{km}$ resolution. Compared with an observational analysis, the overall spatial and temporal evolution of simulated rainfall and circulation reveals the capability of MPAS for reproducing equatorial Kelvin waves (KWs), and the interactions with equatorial Rossby waves and off-equatorial mixed Rossby-gravity (MRG)/TD-type waves up to a 5-7-day lead in both fixed 60-km and variable 60-15-km resolutions. Two interaction events are further examined. One involves an MRG/TD wave, prevailing northeasterlies, and a Borneo vortex developed in SCS during 6-11 December. The other involves a KW converging with the easterly trade wind that led to an MRG/TD-type wave and the formation of Typhoon Nock-ten during 16-20 December. The MPAS 60-15-km resolution tends to produce stronger precipitation and more coherent vorticity structures in both interaction events. Increasing the resolution to $15 \mathrm{~km}$ contributes to better representation of finer spatial vorticity and rainfall structures.
\end{abstract}

\section{Introduction}

The South China Sea (SCS) and Maritime Continent (MC) regions are located at the center of the IndoPacific warm pool, where tropical convection establishes the rising branch of both the Hadley cell and Walker circulation and plays a critical role in the Asian-Australian monsoon system (Chang et al. 2005). Tropical waves are typically active in the entire year in the SCS-MC. These periodically and zonally propagating modes of tropical convection at different temporal and spatial scales contribute to considerable multiscale convective variability. This region also has contrasting land-ocean difference, complex coastlines, and steep topography, making the convective processes even more complicated. Therefore, it is of importance to understand the

Corresponding author: Chung-Hsiung Sui, sui@as.ntu.edu.tw initiation and organization of the multiscale convective features in the SCS-MC and to simulate/forecast them in the global atmospheric models (Birch et al. 2015).

Previous analyses of space-time spectra of tropical convection data fit the dispersion relation of equatorial waves [Kelvin wave (KW), Rossby (ER) wave, mixed Rossby-gravity (MRG) wave, and the tropical depression (TD)-type disturbance], suggesting that tropical waves are convectively coupled (Takayabu and Nitta 1993; Wheeler and Kiladis 1999; Roundy and Frank 2004; Frank and Roundy 2006). However, the structure and wave properties of these observed convectively coupled waves still bear substantial differences to those based on the linear equatorial beta-plane shallow-water theory (Matsuno 1966; Lindzen 1967), due to the modulation by latent heat release and the moist convective processes. Frank and Roundy (2006) proposed that the MRG and TD-type bands can be considered together 
because of the overlapping wavenumber-frequency spectra in tropical wave analysis. This kind of MRG/TDtype disturbance is characterized by enhanced low-level vorticity and large-scale convection and are sometimes associated with tropical cyclogenesis, especially in the Northern Hemisphere (e.g., Chang et al. 2003, 2005; Schreck and Molinari 2011).

Plentiful tropical-extratropical interactions occur in the SCS-MC region during the East Asian winter monsoon. Cold surges originate from the Siberian high in the midlatitudes often extend equatorward into this region (Ramage 1968; Chang et al. 2005, 2006, 2016; Wu et al. 2007). As the northeasterly cold surges and equatorial westerlies encounter, low-level cyclonic vorticity is often accumulated associated with the distribution of the island topography around the SCS region. Perturbations that amplify into synopticscale low-level cyclones over northwestern Borneo, called Borneo vortices (BV; Johnson and Houze 1987), are typically associated with deep convection and intense latent heat release (Cheang 1977; Lau and Chang 1987; Johnson and Houze 1987; Chang et al. 2003; Trilaksono et al. 2012; Chang et al. 2016). A BV may also interacts with other types of tropical waves and oscillations and sometimes develop into a tropical cyclone near the equator (Chang et al. 2003, 2005).

To understand the influences of convectively coupled KWs on multiscale rainfall variability in the SCS-MC, Chen et al. (2019) performed a systematic analysis of the KWs, ERs, and MRG/TD (MT) waves and their interaction with topography in the SCS for December 2016 [Fig. 1, adopted from Chen et al. (2019)]. The climatological background in that month was under La Niña conditions. The western Pacific to eastern Indian Ocean (IO) had $0.5^{\circ}$ to $2^{\circ} \mathrm{C}$ warmer SSTs and more convective activity than climatology while eastern Pacific and central IO had lower SST and downward motion unfavorable for convective development. For synoptic-scale weather systems to intraseasonal oscillations over the equator, there are two convectively coupled KWs (i.e., KW2 and KW3) accompanied by equatorial westerlies and deep convection that move eastward from eastern IO to western Pacific. In the off-equatorial area, four prominent deep convective systems propagate westward, including a BV (Fig. 1, star 2) and two tropical cyclones [TCs (Fig. 1, star 1 and star 4)]. These TCs were associated with an ER wave and an MT wave. In addition, the analysis from Chen et al. (2019) reveals multiscale interactions between weather systems and topography. In early December, climatological westerly wind over eastern IO was enhanced by arriving ER waves and deep convection appeared to the west of Sumatra due to the wind-terrain interaction. KW then

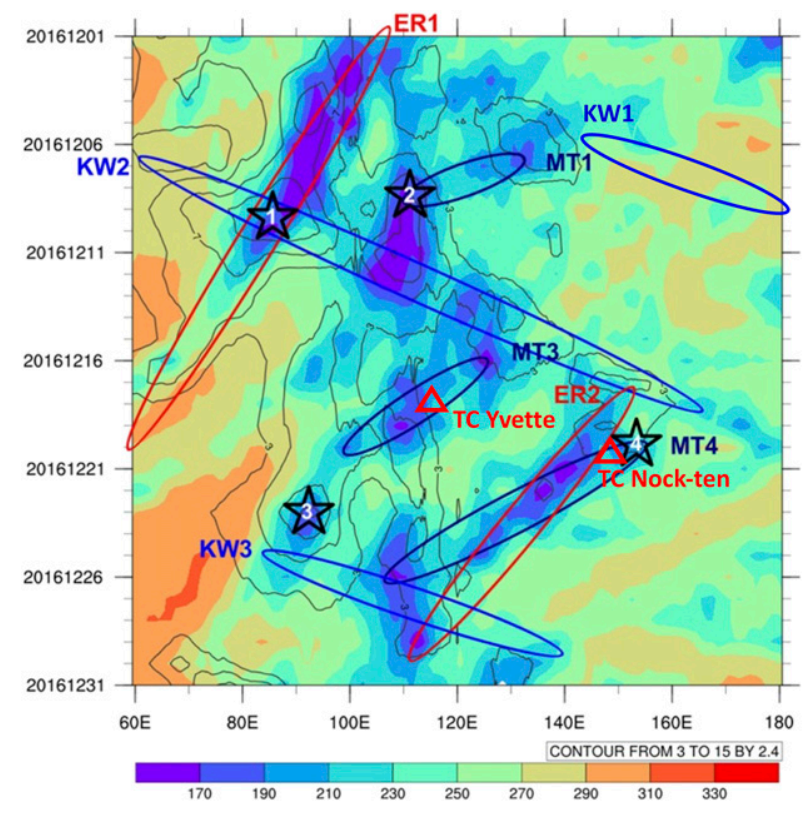

FIG. 1. A schematic Hovmöller diagram of total OLR averaged over $5^{\circ}-15^{\circ} \mathrm{N}$ (shaded) and $925-\mathrm{hPa}$ westerly wind averaged over $5^{\circ} \mathrm{S}-5^{\circ} \mathrm{N}$ (contours) from Chen et al. (2019), illustrating multiscale interaction in December 2016. The elongated ellipses represent Kelvin waves (KW, blue), equatorial Rossby waves (ER, red), and mixed Rossby-gravity/TD-type waves (MT, navy). The star symbol with the number indicates the location and time of a scale interaction event. Star 1 is the wind-terrain interaction between ER1 and TC Vardah at about $85^{\circ} \mathrm{E}$, which enhances KW2 and is coupled with the deep convection. Star 2 denotes the interaction between the winter monsoon and the Borneo vortex formed in South China Sea (SCS). Star 3 denotes the interaction between MT3 and the winter monsoon that enhances KW3. Star 4 is the event when Tropical Cyclones Yvette and Nock-ten formed (red triangle) associated with westerly winds brought by KW2 and easterly trade winds over the western North and South Pacific. The passage of KW3 over the Maritime Continent also coincides with the Australian summer monsoon onset during 11-15 Dec (ER2).

amplified and coupled with the deep convection. A BV formed through cold surge affected by the terrains surrounding the SCS and was strengthened with the help of cyclonic circulation provided by MT wave. Around the 18 December, tropical depression 06U, TCs Yvette and Nock-ten formed almost simultaneously from the cyclonic circulation produced by the interaction between easterly trade wind and KWs. Deep convection initiated over the east coast of Vietnam and the Philippine was noticeable due to northeasterlies-terrain interaction and its activity was modulated by MT waves. The passage of the KW over Maritime Continent also coincided with Australian summer monsoon onset during 11-15 December.

The Madden-Julian oscillation (MJO, Madden and Julian 1972) has been reported as one of the dominant modes of convective activity in tropics and may be one 
of the precursors for enhancing the predictability of subseasonal-to-seasonal forecasts (Vitart et al. 2015; White et al. 2017). Many previous studies also study the performance of the MJO forecasts with either operational or research models (e.g., Vitart 2014; Pilon et al. 2016). The MJO, however, was inactive over the SCSMC region in December 2016, the KWs and its interactions with ERs and MT waves play the dominant roles in the convective activity (Chen et al. 2019). The eastward-propagating KWs can be either part of the MJO convective envelope (Majda and Khouider 2004; Mapes et al. 2006; Gottschalck et al. 2013) or an independent convectively coupled wave in tropics (Dunkerton and Crum 1995; Wheeler and Kiladis 1999). The KWs can enhance the tropical convections on synoptic scales (e,g., Wheeler and Kiladis 1999; Wheeler et al. 2000; Wang and Fu 2007; Yanase et al. 2010; Ventrice et al. 2012) and provide background cyclonic vorticity that favors TC genesis (Schreck and Molinari 2011; Schreck 2015).

As the scale interaction events between low-frequency flow (KWs, winter monsoon) and synoptic disturbances (MTs, BV) over the SCS-MC play the dominant roles in the convective activity in December 2016, this study follows up the efforts of Chen et al. (2019) and evaluates the model simulation of the interaction events during December 2016 with a series of hindcast experiments made by Model for Prediction Across Scales (MPAS). Specifically, MPAS experiments with a uniform $60-\mathrm{km}$ resolution and a $60-15-\mathrm{km}$ variable resolution are conducted. The model configuration with the $60-15-\mathrm{km}$ variable mesh is used for the currently operational MPAS forecast system in National Science and Technology Center for Disaster Reduction (NCDR), Taiwan ${ }^{1}{ }^{\text {this }}$ model configuration could be a solution to directly downscale the simulation results from large scale to regional scale, aiming to predict the rainfall around Taiwan, the SCS, and the western Pacific up to 2 weeks.

The goal of this study is to examine the model capability of simulating the tropical intraseasonal oscillations (10-20-day KWs in this study) and its interaction with synoptic-scale events in the SCS-MC and the western Pacific up to 5-10 days. To accomplish the goal, we first compare the hindcasts by MPAS with uniform $60-\mathrm{km}$ and variable $60-15-\mathrm{km}$ resolutions to evaluate the overall hindcast performance of large-scale circulation associated with tropical intraseasonal oscillation. Subsequently, hindcasts of two cases of scale interaction events in December 2016 are further examined to

\footnotetext{
${ }^{1}$ Operational MPAS products of NCDR is available at https:// watch.ncdr.nat.gov.tw/watch_mpas2weeks.
}

evaluate the hindcast performance of synoptic disturbances with the two resolution setups. The above model performance hinges on the following hypotheses: the model with $60-15-\mathrm{km}$ variable resolution can better resolve convection-coupled synoptic-scale events; the convection-coupled events feedback to large-scale flow to result in better hindcasts performance. In principle, the model performance depends on the fidelity of representation of convection-radiation interacting with large-scale waves disturbances in the model up to extended-range (5-10 days) weather prediction. In these regards, the evaluation of hindcast results of fixed and variable resolutions provides an in-depth case study to examine the hypotheses.

This paper is organized as follows. A brief introduction of MPAS and experimental design are described in section 2. Section 3 evaluates the overall simulation of large-scale circulation during December 2016 for the two hindcast experiments. Section 4 examines the simulation of two interaction events and the associated synoptic and convective features in the SCS-MC and the western Pacific warm pool. The summary and discussion are provided in section 5 .

\section{Model description and experimental design}

MPAS version 4.0, which is used in this study, is a nonhydrostatic global atmospheric model with unstructured centroidal Voronoi mesh and C-grid staggering of the state variables (Skamarock et al. 2012). MPAS allows variable-resolution configurations that are generated with a smooth transition area of varying grid size. Previous idealized experiments have shown that the variable-resolution mesh can reduce numerical errors associated with the wave propagation through different resolution areas in the traditional nested grid of regional models (Skamarock et al. 2012; Hagos et al. 2013; Park et al. 2014). Pilon et al. (2016) simulated the MJO events during the Dynamics of the Madden Julian Oscillation (DYNAMO) field campaign (Yoneyama et al. 2013) with MPAS 60-, 15-, and 50-3-km-resolution meshes. Their hindcast experiments indicate that the use of Tiedtke scheme with its shallow convection components and WSM6 microphysics can improve the largescale organization of MJO events and produce strong MJO-like signals in precipitation. Changing model grid spacing from 60 to $15 \mathrm{~km}$ makes a little difference in the model fidelity of reproducing MJO. Davis et al. (2016) evaluate the MPAS 10-day forecasts for eastern Pacific tropical cyclones in 2014 by using a uniform $15-\mathrm{km}$ mesh and a variable $60-15-\mathrm{km}$ mesh. The forecast skill is comparable to the NCEP GFS. The forecast results for variable and uniform configurations of MPAS are very 
similar in most cases through day 7 , which suggest the effectiveness of TC prediction using variable resolution. MPAS also has been used to simulate typhoons and precipitation structures over terrain, and the interaction between MJO-scale flows and typhoon motions (Huang et al. 2017).

Two sets of hindcast experiments are conducted in this study. The first set was made with uniform $60-\mathrm{km}$ resolution. The second set was made with $60-15-\mathrm{km}$ variable resolution. The higher resolution area of $15-\mathrm{km}$ was centered at $20^{\circ} \mathrm{N}, 140^{\circ} \mathrm{E}$ and covered the area of Taiwan, Philippines, and the SCS, with a transition zone from 15 to $60 \mathrm{~km}$ in the surrounding boundary and $60-\mathrm{km}$ resolution in the rest of the globe (Fig. 2). Note that the transition zone near the equator and Southern Hemisphere may lose some accuracy in simulating synoptic convection structure in equator and Australian summer monsoon in the Southern Hemisphere. Furthermore, MPAS used the hybrid terrain-following height coordinate (Klemp 2011) with 41 model levels and the model top was set at about $28 \mathrm{~km}$ in this study. Model physics used in our simulation included the Weather Research and Forecasting Model single-moment 6-class microphysics scheme (WSM6; Hong and Lim 2006), the Tiedtke convective cumulus scheme (Zhang et al. 2011), Yonsei University (YSU) planetary boundary layer parameterization (Hong et al. 2006), Monin-Obukhov surface-layer parameterization, the Noah land surface model, and the Rapid Radiative Transfer Model for GCM applications (RRTMG) longwave and shortwave radiation parameterizations (Iacono et al. 2008).

Both sets of simulations were initialized with National Centers for Environmental Prediction (NCEP) Global Forecast System (GFS) analysis data on $0.5^{\circ} \times 0.5^{\circ}$ grids (National Centers for Environmental Prediction/National Weather Service/NOAA/U.S. Department of Commerce 2007). The first set of hindcast experiments with $60-\mathrm{km}$ uniform resolution comprised of sequential runs starting every 3.5 days, and the integration period of each hindcast was 10.5 days. A total of 11 hindcasts were made with the first one starting at 0000 UTC 24 November. On the other hand, the second set of hindcast experiments with $60-15-\mathrm{km}$ variable resolution comprised 33 simulations of 10-day duration starting at 0000 UTC every day, with 29 November as the first day.

For each hindcast, the initial values of sea surface temperature (SST) are set with the skin temperature of the GFS analysis; SST is fixed in time without update during simulation. No data assimilation was used in all the experiments. Since NCEP-GFS data has a resolution of $0.5^{\circ}$, for comparing with the observational data, all simulation variables were regridded into $0.5^{\circ} \times 0.5^{\circ} \mathrm{mesh}$.

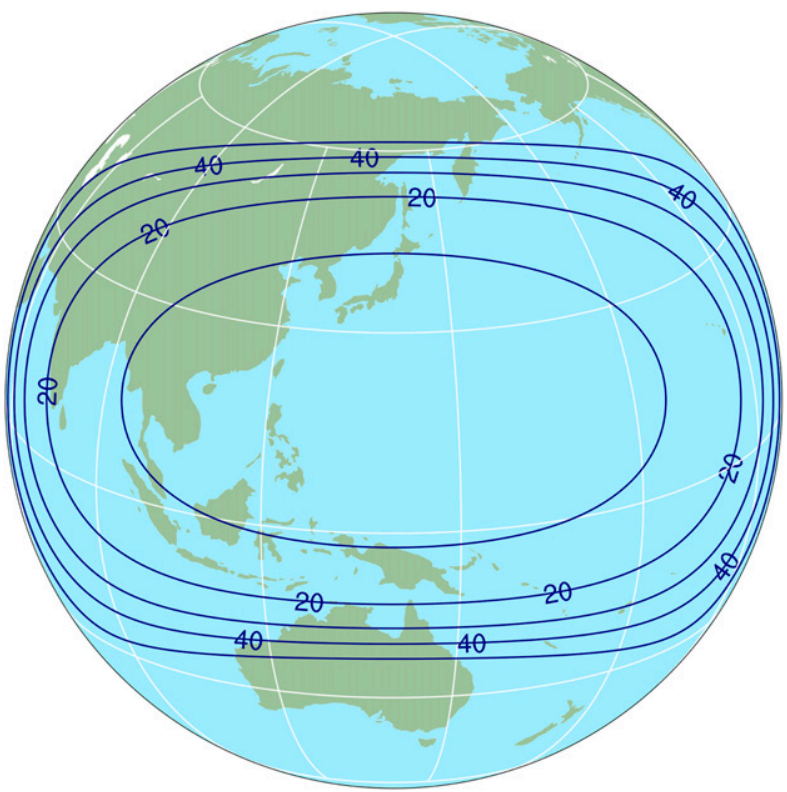

FIG. 2. A variable-resolution mesh from 60 to $15 \mathrm{~km}$. Grid resolutions are contoured at $15,20,30,40$, and $50 \mathrm{~km}$. The $15-\mathrm{km}$ refinement area is centered at $20^{\circ} \mathrm{N}, 140^{\circ} \mathrm{E}$.

\section{Evaluation of the simulated overall submonthly variability}

As shown in Fig. 3a, the submonthly variability in December 2016 were dominated by three Kelvin waves, which was indicated by the $5^{\circ} \mathrm{S}-5^{\circ} \mathrm{N}$ averaged precipitation [retrieved from Global Precipitation Measurement (GPM) products; Huffman et al. (2017a,b)] and westerly winds at $925 \mathrm{hPa}$ (NCEP FNL reanalysis data; National Centers for Environmental Prediction/National Weather Service/NOAA/U.S. Department of Commerce 2000). Figures $3 \mathrm{~b}-\mathrm{d}$ are similar Hovmöller diagrams of the 60-km MPAS simulated rain and wind for 0-3.5-, 3.5-7-, and 7-10.5-day lead times, respectively. There are two convective signals initiated at around $90^{\circ} \mathrm{E}$ and accompanied by westerly winds, propagating eastward and dissipating at around $160^{\circ} \mathrm{E}$. The $0-3.5$-day simulation (Fig. 3b) shows the characteristics of convectively coupled equatorial waves over the equatorial region, where the convection collocates with westerly winds. The MPAS also simulates the eastward propagation of the deep convection signals that initiate on 6 December, though the precipitation maxima are weaker than the observations. On the other hand, the KW initiated at $90^{\circ} \mathrm{E}$ on 21 December can be identified with the precipitation and westerly winds pattern, but the precipitation amount between $90^{\circ}$ and $140^{\circ} \mathrm{E}$ is overestimated. The convection become more diffusive and disorganized for the 3.5-7- and 7-10.5-day lead times (Figs. 3c,d). In general, MPAS well simulated the large-scale flow 

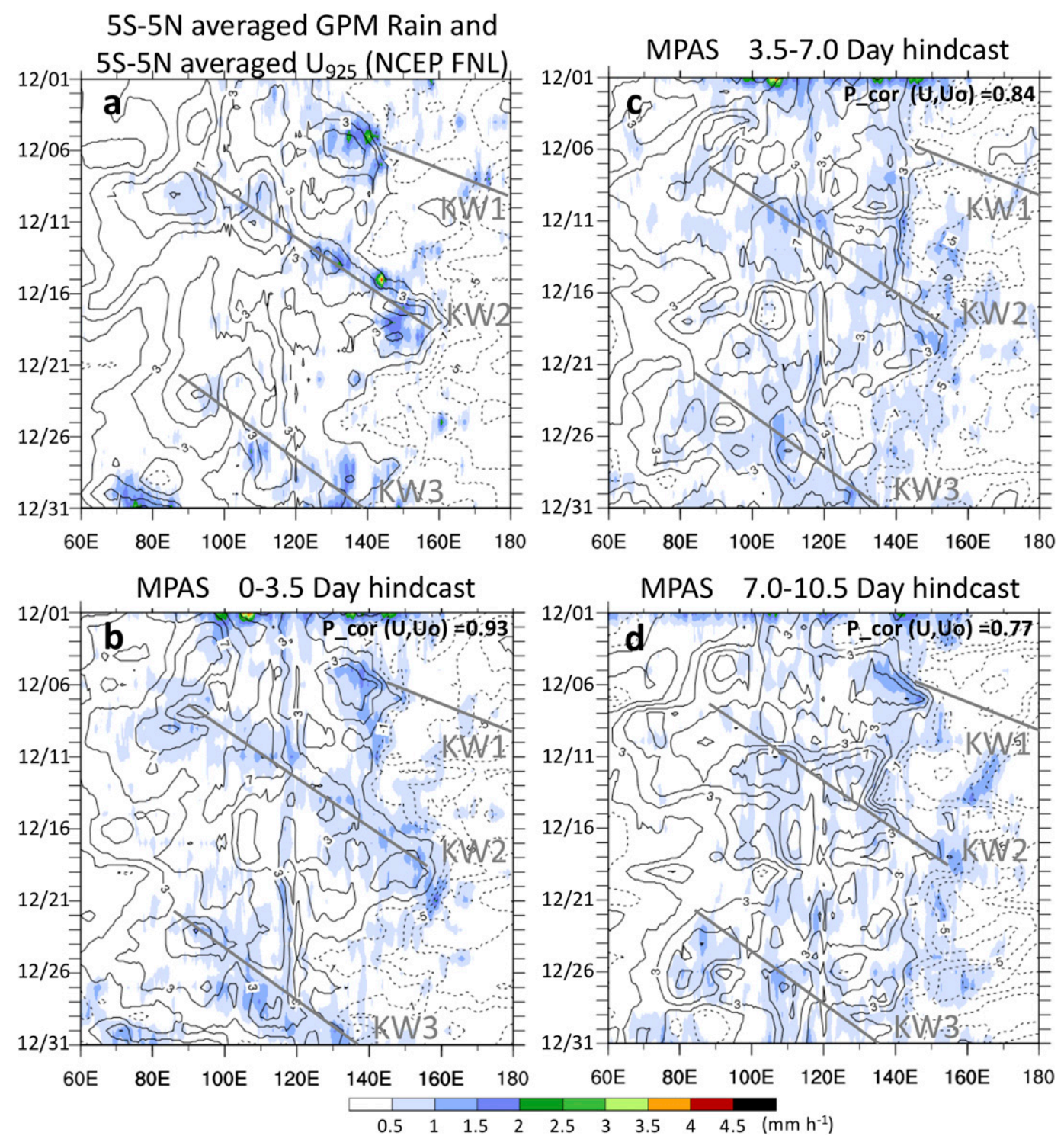

FIG. 3. (a) Hovmöller diagram of $5^{\circ} \mathrm{S}-5^{\circ} \mathrm{N}$-averaged precipitation (shaded, from GPM) and zonal winds at $925 \mathrm{hPa}$ (contoured from -15 to $15 \mathrm{~m} \mathrm{~s}^{-1}$ every $2 \mathrm{~m} \mathrm{~s}^{-1}$, dashed for negative, from NCEP FNL) in December 2016. (b)-(d) As in (a), but for the MPAS 60-km simulation at 0-3.5-, 3.5-7-, and 7-10.5-day lead times, respectively. Three gray lines indicate Kevin waves identified based on space-time-filtered OLR data. The pattern correlations of observed and simulated zonal winds are $0.93,0.84$, and 0.77 in (b)-(d), respectively.

pattern. The correlation coefficients $R$ of $925-\mathrm{hPa}$ zonal winds $U$ between that in Fig. 3a and those in Figs. 3b-d are 0.93, 0.84, and 0.77 for 0-3.5-, 3.5-7-, and 7-10.5-day lead.

The observation and simulated fields of precipitation and winds in Fig. 3 are further compared quantitatively by $R$ of precipitation $P$, vorticity $\zeta$, and divergence $\delta$ (Tables 1-3 ). In addition to the simulations by the 60 $\mathrm{km}$ experiment, we also show in Tables $1-3 R$ for $60-15$ $\mathrm{km}$ simulations. Three lead-time periods of $0-3.5(0-3)$, $3.5-7$ (3-6), and 7-10.5 (6-9) days for the $60(60-15)-\mathrm{km}$ simulations are denoted as $\mathrm{T} 1, \mathrm{~T} 2$, and $\mathrm{T} 3$, respectively.
In the equatorial region, $R$ of $P$ for the $60-\mathrm{km}$ experiment are about $0.66-0.61$ from period $\mathrm{T} 1$ to $\mathrm{T} 3$, while $R$ for the $60-15-\mathrm{km}$ experiment are about $0.71-0.60$. Furthermore, $R$ of $\zeta$ are better than that of $P$ in the first two periods: $0.78(0.81), 0.66(0.65)$, and $0.49(0.56)$ for the $60-$ and $60-15-\mathrm{km}$ experiments in $\mathrm{T} 1, \mathrm{~T} 2$, and $\mathrm{T} 3$, respectively. The performance of $\delta$ is relatively worse than the previous two fields. The $R$ is $0.52(0.47), 0.52$ (0.33), and $0.46(0.28)$ for the $60(60-15)$-km experiments in T1 and T2. Note that $R$ of $\delta$ remain about 0.5 on average in the three periods for the $60-\mathrm{km}$ experiment, 
TABLE 1. Daily averaged correlation coefficients between observed and MPAS simulated precipitation $P$ for three latitudinal bands $\left(15^{\circ}-5^{\circ} \mathrm{S}, 5^{\circ} \mathrm{S}-5^{\circ} \mathrm{N}\right.$, and $\left.5^{\circ} \mathrm{N}-15^{\circ} \mathrm{N}\right)$ of $60^{\circ} \mathrm{E}-180^{\circ}$ in December 2016. Three lead-time periods of 0-3.5, 3.5-7, and $7-10.5$ days for the $60-\mathrm{km}$ experiment and $1-3,4-6$, and $7-9$ days for the $60-15-\mathrm{km}$ experiment are denoted as $\mathrm{T} 1, \mathrm{~T} 2$, and $\mathrm{T} 3$, respectively. In each cell the first value is for the $60-\mathrm{km}$ experiment and the second value is for the $60-15-\mathrm{km}$ experiment.

\begin{tabular}{lccc}
\hline \hline & $5^{\circ} \mathrm{S}-5^{\circ} \mathrm{N}$ & $5^{\circ}-15^{\circ} \mathrm{N}$ & $15^{\circ}-5^{\circ} \mathrm{S}$ \\
\hline T1 & $0.66,0.71$ & $0.61,0.67$ & $0.69,0.74$ \\
T2 & $0.59,0.63$ & $0.52,0.54$ & $0.60,0.65$ \\
T3 & $0.61,0.60$ & $0.52,0.49$ & $0.50,0.59$ \\
\hline
\end{tabular}

but drop from 0.47 to 0.28 (with an average of 0.36 ) for the $60-15-\mathrm{km}$ experiment. These results reveal that although MPAS simulate a reasonable large-scale flow field in terms of vorticity and rainfall, the simulated divergence as a major signal of $\mathrm{KW}$ is worse. This fact may reflect that both boundary layer moisture and wind are constrained by the SST distribution that is given as initial condition and fixed in time while divergence is determined by model convection coupled dynamics. Furthermore, the $R$ values of $P, \zeta$, and $\delta$ for both the 60and $60-15-\mathrm{km}$ experiments are comparable (Tables $1-3$ ), implying that the variable-resolution configuration does not lead to a significant better representation of the large-scale flow in this case.

The observed and simulated zonal-temporal evolutions of $5^{\circ}-15^{\circ} \mathrm{N}$ averaged precipitation are examined in Fig. 4. The westward-propagating off-equatorial cyclonic disturbances are well simulated in MPAS. Specifically, the ER1/Cyclone Vardah, BV, and ER2/ Cyclone Nock-ten are clearly simulated for 0-3.5- and 3.5-7-day lead times (Figs. 4b,c). However, the MT3 event only has weak signal for 0-3.5-day lead time (Fig. 4b), and is missed for longer lead times (Figs. 4c,d). Furthermore, the simulated ER1/Vardah cyclone is formed earlier than the observation (Figs. 4b-d), but still propagates westward. The BV during 6-11 December is captured for all three lead times. The interaction of KW2 (Fig. 4, contour; see also Fig. 3) and Nock-ten on 16 December is clearly revealed for 0-3.5- and 3.5-7-day lead times (Figs. 4b,c). The Nock-ten signal and the westerly wind field around $140^{\circ}-150^{\circ} \mathrm{E}$ is relatively weak in 7-10.5-day range, suggesting a weak interaction between KW2 and Nock-ten (Fig. 4d). The $R$ of $\zeta$ in $5^{\circ}-$

TABLE 2. As in Table 1, but for 925-hPa vorticity $\zeta$ for NCEP-FNL vs MPAS simulations.

\begin{tabular}{lccc}
\hline \hline & $5^{\circ} \mathrm{S}-5^{\circ} \mathrm{N}$ & $5^{\circ}-15^{\circ} \mathrm{N}$ & $15^{\circ}-5^{\circ} \mathrm{S}$ \\
\hline T1 & $0.78,0.81$ & $0.70,0.75$ & $0.77,0.83$ \\
T2 & $0.66,0.65$ & $0.52,0.50$ & $0.58,0.58$ \\
T3 & $0.49,0.56$ & $0.46,0.38$ & $0.53,0.46$ \\
\hline
\end{tabular}

TABLE 3. As in Table 1, but for 925-hPa divergence $\delta$ for NCEPFNL vs MPAS simulations.

\begin{tabular}{lccc}
\hline \hline & $5^{\circ} \mathrm{S}-5^{\circ} \mathrm{N}$ & $5^{\circ}-15^{\circ} \mathrm{N}$ & $15^{\circ}-5^{\circ} \mathrm{S}$ \\
\hline $\mathrm{T} 1$ & $0.52,0.47$ & $0.53,0.57$ & $0.58,0.59$ \\
$\mathrm{~T} 2$ & $0.52,0.33$ & $0.38,0.42$ & $0.45,0.39$ \\
$\mathrm{~T} 3$ & $0.46,0.28$ & $0.36,0.39$ & $0.42,0.26$ \\
\hline
\end{tabular}

$15^{\circ} \mathrm{N}$ for three lead times are $0.70,0.52$, and 0.46 . The $R$ for $\delta(P)$ are $0.53(0.61), 0.38(0.52)$, and $0.36(0.52)$; see the second columns of Tables $1-3$. While $R$ of divergence in $5^{\circ} \mathrm{S}-5^{\circ} \mathrm{N}$ are comparable to $R$ of divergence in $5^{\circ}-15^{\circ} \mathrm{N}$ and $5^{\circ}-15^{\circ} \mathrm{S}, R$ of vorticity is generally larger than $R$ of divergence, indicating rotation wind is better simulated than divergence wind. The results of $60-15$ $\mathrm{km}$ experiments in the off-equatorial region are similar to that of the equatorial region. The simulations using $60-15-\mathrm{km}$ variable resolution does not show significant improvement in large-scale features.

Further analysis of daily pattern correlations of various lead days is provided in Fig. 5. For example, Fig. 5a shows the spatial $\mathrm{R}$ of simulated rainfall and GPM rainfall over $20^{\circ} \mathrm{S}-20^{\circ} \mathrm{N}, 90^{\circ} \mathrm{E}-180^{\circ}$ at different lead days (Fig. 5a). For each lead day, a distribution of $R$ is created based on simulations with various initial times (i.e., every 3.5 days for the $60-\mathrm{km}$ experiment and every day for the $60-15-\mathrm{km}$ experiment). In general, $R$ of rainfall are about 0.5 to 0.2 from 1 - to 10 -day lead times (Fig. 5a). Note that $R$ in Fig. 5 are generally lower than the $R$ in Tables $1-3$, in which $R$ is calculated based on variables averaged in $10^{\circ}$-latitude bands.

As shown in Fig. 5a, the spatial $R$ of rainfall are almost identical for 60 - and $60-15-\mathrm{km}$ experiments. In addition, Figs. $5 \mathrm{~b}$ and $5 \mathrm{c}$ are the $R$ of vorticity over $5^{\circ}-20^{\circ} \mathrm{N}, 90^{\circ} \mathrm{E}-$ $180^{\circ}$ and $5^{\circ}-20^{\circ} \mathrm{S}, 90^{\circ} \mathrm{E}-180^{\circ}$. Whereas $R$ for vorticity over $5^{\circ}-20^{\circ} \mathrm{N}$ is about 0.6 for the first day and become about 0.3 after 5 days, $R$ for vorticity over $5^{\circ}-20^{\circ} \mathrm{S}$ is about 0.7 for the first day but decay to about 0.2 after 5 days. The $R$ of vorticity for the $60-15-\mathrm{km}$ experiment are slightly higher than that for the $60-\mathrm{km}$ experiment. A two-sample Student's $t$ test was applied to test the statistical significance of the null hypothesis that the mean $R$ of vorticity are significantly comparable between the two experiments (comparing the blue and red lines in Fig. 5). The results confirm that the $60-15-\mathrm{km}$ simulation has a statistically higher $R$ of vorticity at the simulation time of one day than that of the $60-\mathrm{km}$ experiment at the $95 \%$ confidence level, but $R$ of vorticity are statistically comparable for rest of the simulation. Recalling that Table 3 implies a comparable performance of the 60-15and $60-\mathrm{km}$ simulations from a large-scale perspective based on $R$ of meridionally averaged variables. However, $R$ of spatial fields of divergence in Figs. 5d and 5e suggest 


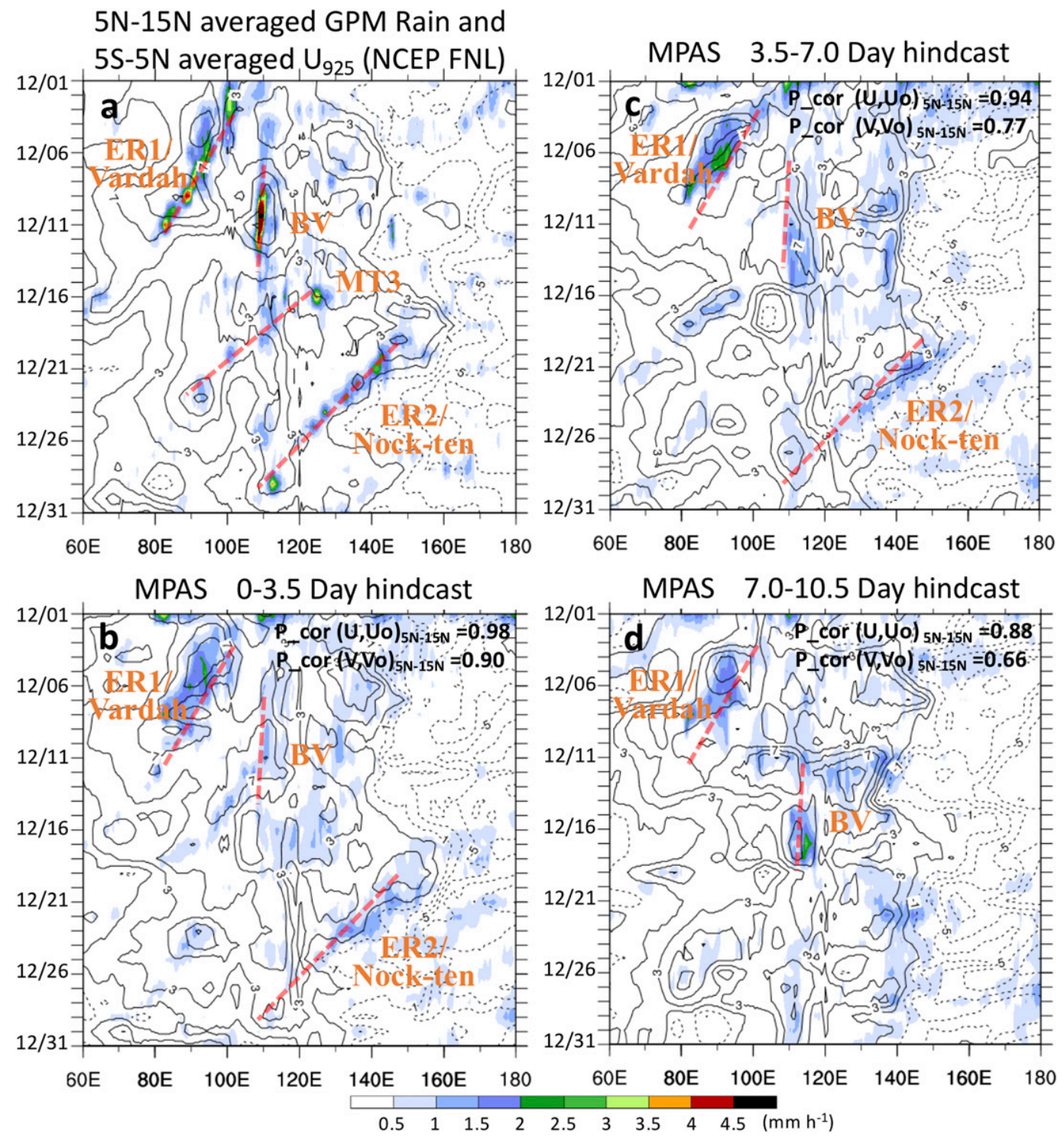

FIG. 4. As in Fig. 3, but precipitation is averaged in the $5^{\circ}-15^{\circ} \mathrm{N}$ latitudinal band. The correlation coefficients of observed and simulated $u$ and $v$ are $0.98,0.94$, and 0.88 and $0.90,0.77$, and 0.66 for $0-3.5-, 3.5-7.0-$, and 7.0-10.5-day lead times, respectively.

that the $60-15-\mathrm{km}$ simulation better resolves the convective activity in terms of divergence than the $60-\mathrm{km}$ simulation. The 60-km simulation has weaker and more blurry divergence pattern associated with organized convective systems (not shown), and thus has lower spatial-pattern $R$ values. Specifically, $R$ of divergence for the $60-15-\mathrm{km}$ experiment in the Northern Hemisphere (Fig. 5d, red line) drops from approximately 0.6 to approximately 0.3 with a smooth decay rate after 5 days, while the $R$ of divergence for the $60-\mathrm{km}$ experiment, which drops from 0.4 to 0.2 , fails the significance test at the $95 \%$ confidence level.
In summary, our results show that MPAS produces skillful simulations of the KW, ER, and MT wave signals in December 2016 up to 5-day lead and the performance of vorticity is usually better than that of rainfall and divergence. Increasing the resolution to $15 \mathrm{~km}$ does not show significant improvement for simulating the average wave structures and large-scale circulation. Nevertheless, day-by-day spatial correlation analysis of $60-15-\mathrm{km}$ displays some benefit in the divergence fields, implying that increasing the resolution is likely to improve the simulation of convective synoptic circulation. In the next section, we chose two cases of scale interaction from 3 to 

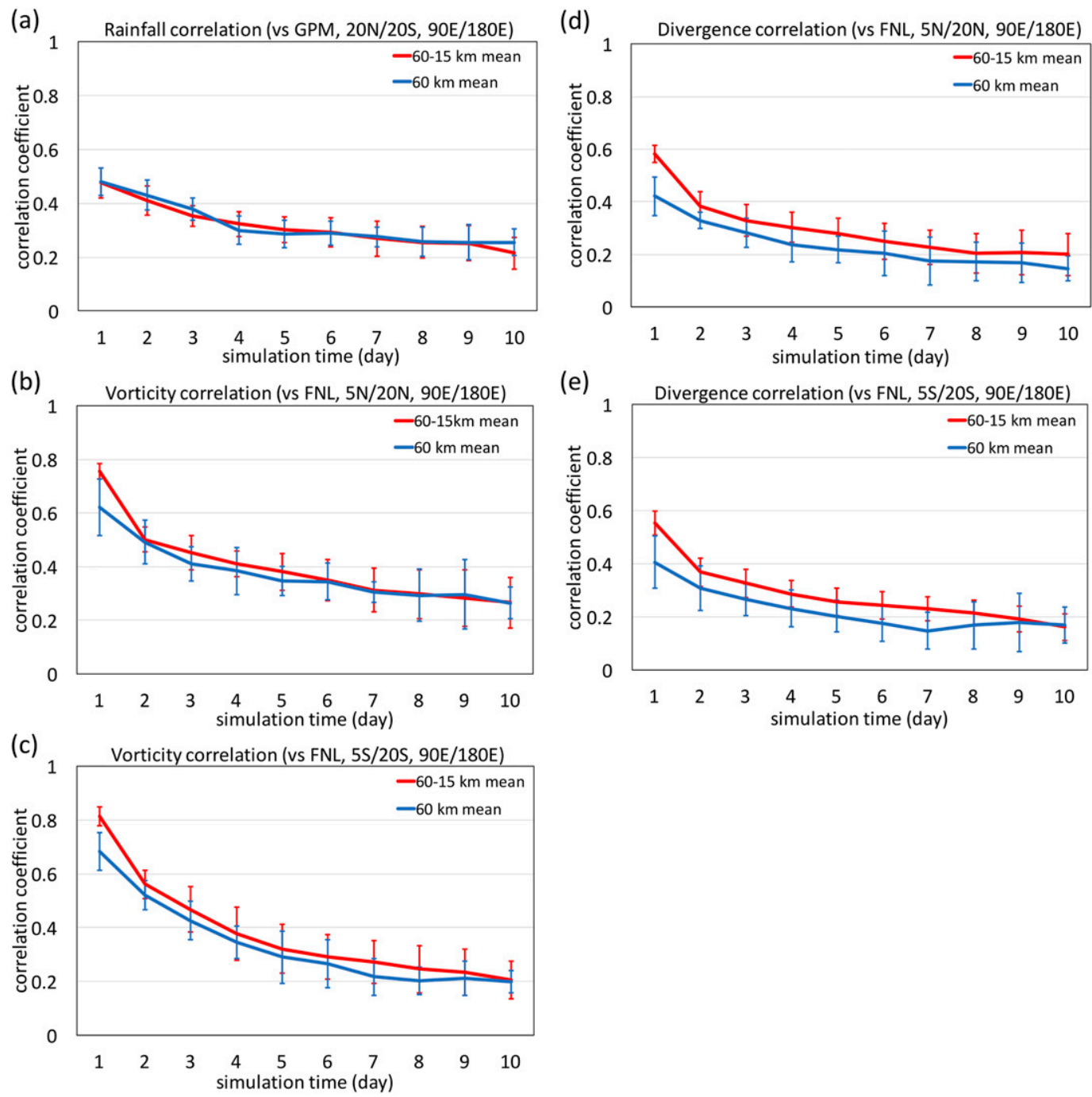

FIG. 5. (a) Spatial-pattern correlation coefficients of rainfall, over $20^{\circ} \mathrm{S}-20^{\circ} \mathrm{N}, 90^{\circ} \mathrm{E}-180^{\circ}$ between observation and MPAS $60-\mathrm{km}$ (blue) and 60-15-km (red) simulations for various lead times. The mean values, with whiskers indicating one standard deviation, are plotted. (b)-(e) As in (a), but for (b) vorticity at $925 \mathrm{hPa}$ over $5^{\circ}-20^{\circ} \mathrm{N}$, $90^{\circ} \mathrm{E}-180^{\circ}$; (c) vorticity at $925 \mathrm{hPa}$ over $5^{\circ}-20^{\circ} \mathrm{S}, 90^{\circ} \mathrm{E}-180^{\circ}$; (d) $925-\mathrm{hPa}$ divergence over $5^{\circ}-20^{\circ} \mathrm{N}, 90^{\circ} \mathrm{E}-180^{\circ}$; and (e) 925 -hPa divergence over $5^{\circ}-20^{\circ} \mathrm{S}, 90^{\circ} \mathrm{E}-180^{\circ}$.

11 December and from 16 to 20 December as two examples to further compare the synoptic features simulated in the 60- and 60-15-km experiments.

\section{Interaction events in the SCS-MC and the western Pacific warm pool}

\section{a. The simulation of $a B V$ and the associated convective features}

This section examines the simulation of two interaction events and the associated synoptic and convective features in the SCS-MC and the western Pacific warm pool. The first event is regarding the cold surge entering the SCS during 3-11 December and the formation of the associated BV. As shown in Fig. 6, the 6-hourly rainfall and $925-\mathrm{hPa}$ wind of the day-5 simulation for $60-\mathrm{km}$ (Figs. 6b,e,h) and 60-15-km (Figs. 6c,f,i) experiments are compared with the observation (Figs. 6a,d,g). Both the 60 - and $60-15-\mathrm{km}$ experiments fairly simulate the convection developing on the shear line associated with the cold surge entering the northern SCS (i.e., $12^{\circ} \mathrm{N}$, $110^{\circ} \mathrm{E}$ ) on 6 December (Figs. $6 \mathrm{a}-\mathrm{c}$ ). Two days later, on 8 December, a cyclonic circulation (the precursor of the BV) started to form due to the terrain of Indochina Peninsula and Kalimantan around the SCS (Fig. 6d). Both 60- and 60-15-km simulations show the development 

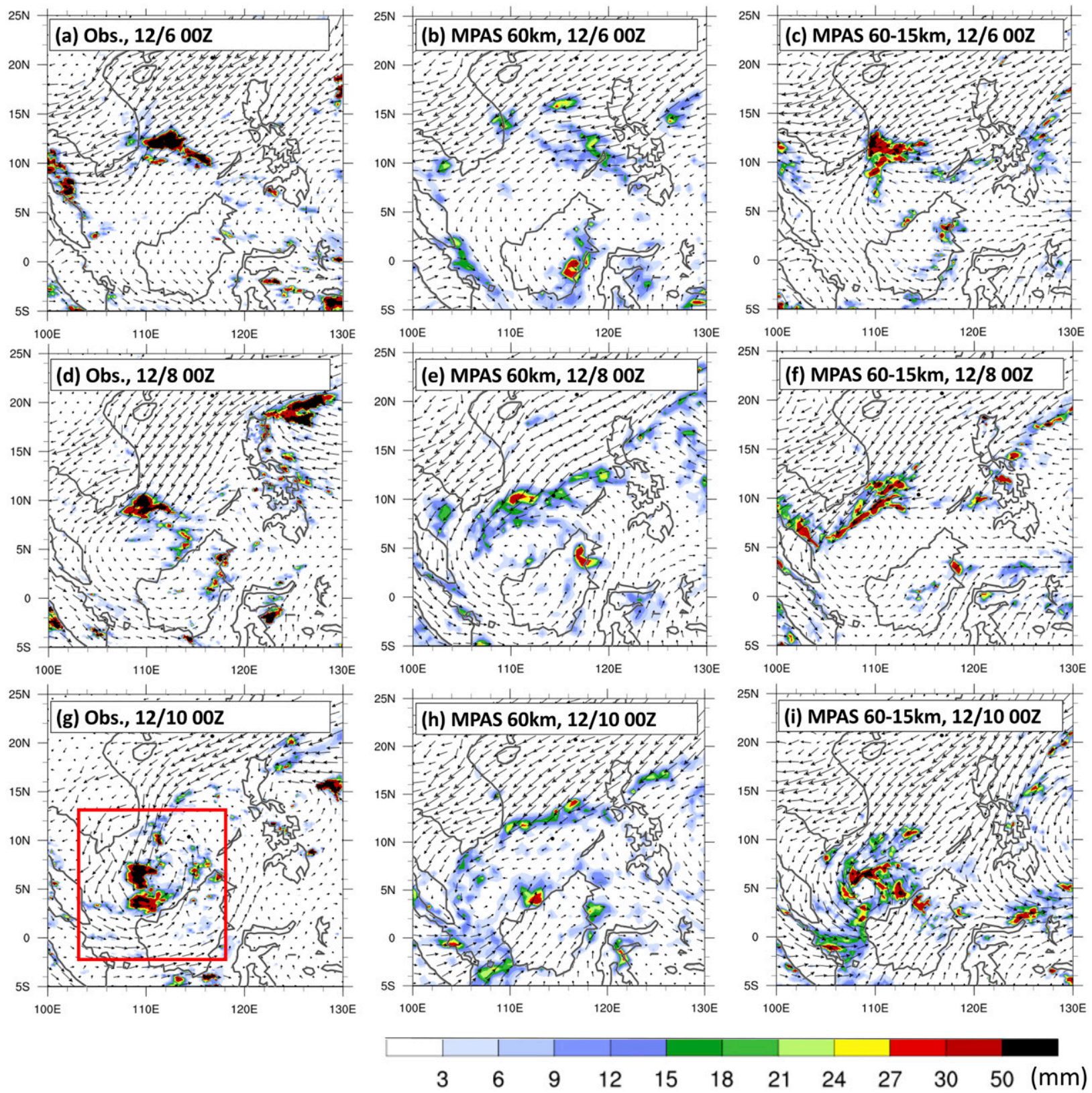

FIG. 6. (left) GPM 6-hourly rainfall and FNL 925-hPa winds and MPAS (center) 60- and (right) 60-15-km simulated 6-hourly rainfall and 925-hPa winds at a lead time of 5 days at (a)-(c) 0000 UTC 6 Dec, (d)-(f) 0000 UTC 8 Dec, and (g)-(i) 0000 UTC 10 Dec.

of a cyclonic circulation in the southern SCS and significant rainfall around $10^{\circ} \mathrm{N}$ in the SCS (Figs. 6e,f). By 10 December, the cyclonic circulation intensified to a Borneo vortex with organized rainfall (Fig. 6g). The formation of a BV and rainfall is well simulated by the two MPAS simulations (Figs. 6h,i). Note that the $60-15-\mathrm{km}$ simulated BV rainfall amount is larger and more consistent with the observations than that of the $60-\mathrm{km}$ simulation. Presumably because the $60-\mathrm{km}$ simulation fails to capture the features of the organized convection (i.e., greater rain rates and larger amount of latent heat release), the $60-15-\mathrm{km}$ result (Fig. 6i) reveals that the cyclonic circulation apparently organizes the convection, and the convection is more axisymmetric and stronger than that of the $60-\mathrm{km}$ result (Fig. 6h).

As the analyses based on Fig. 6 suggest that increasing the resolution to $15 \mathrm{~km}$ leads to a better representation of organized convective features in the simulation, evaluation of some synoptic circulation features including 
(a)

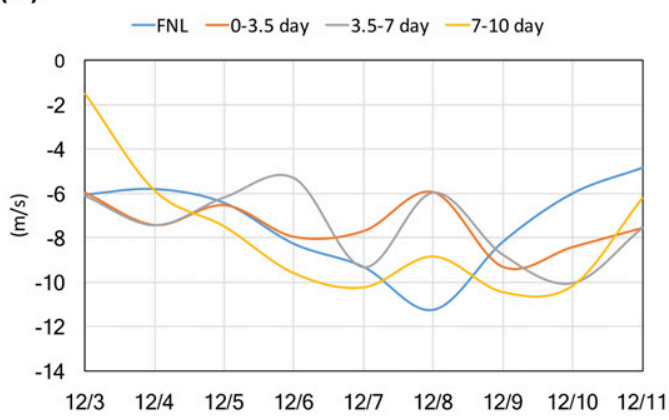

(c)

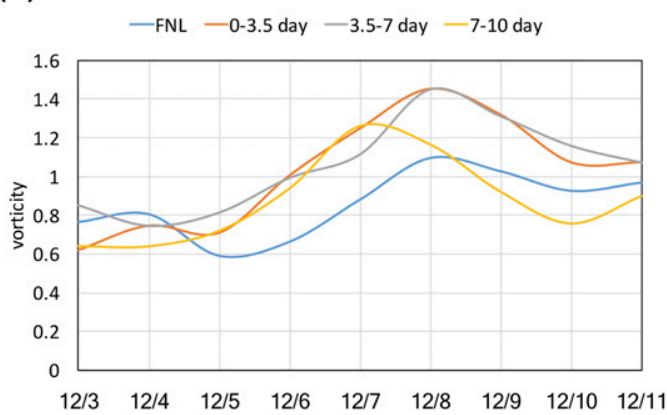

(b) Cold surge index $\left(\mathrm{m} \mathrm{s}^{-1}\right) 60-15 \mathrm{~km}$

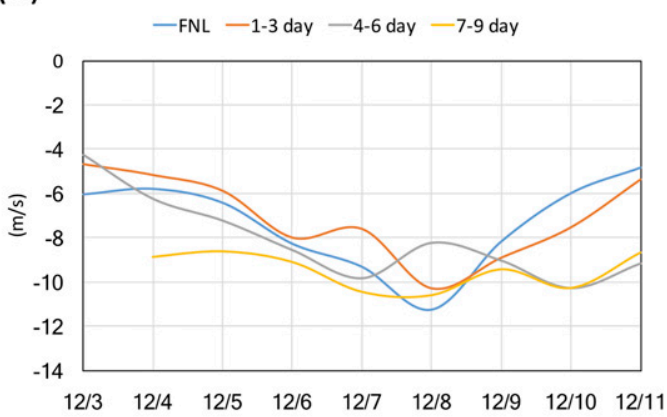

(d) $\quad 925 \mathrm{hPa}$ vorticity $\left(10^{-4} \mathrm{~s}^{-1}\right) 60-15 \mathrm{~km}$

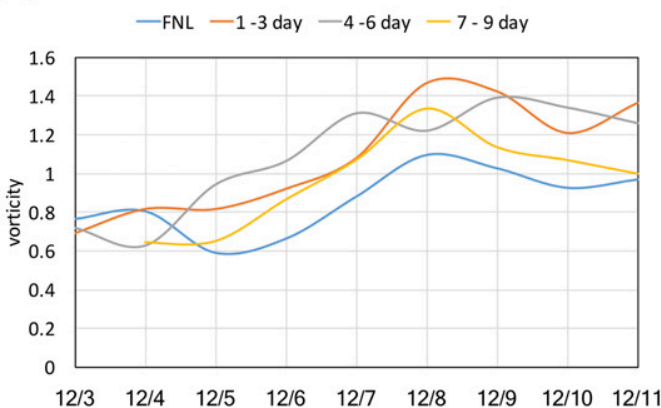

FIG. 7. (a),(b) Cold-surge index (averaged 925-hPa meridional wind between $110^{\circ}$ and $117.5^{\circ} \mathrm{E}$ along $15^{\circ} \mathrm{N}$ ) and (c),(d) averaged 925-hPa vorticity in the red rectangle as indicated in Fig. $6 \mathrm{~g}$ from 3 to 11 Dec for (a), (c) MPAS 60-km simulations and (b),(d) MPAS 60-15-km simulations. The blue line represents observations in NCEP FNL. The orange, gray, and yellow lines respectively represent various lead times of $0-3.5,3.5-7$, and $7-10.5$ days for the $60-\mathrm{km}$ simulation and $1-3,4-6$, and 7-9 days for the $60-15-\mathrm{km}$ simulation.

the cold-surge index and synoptic areal-averaged vorticity for the two experiments is provided in Fig. 7. Following Chang et al. (2005), the cold-surge index, which is defined as the averaged $925-\mathrm{hPa}$ meridional wind between $110^{\circ}$ and $117.5^{\circ} \mathrm{E}$ along $15^{\circ} \mathrm{N}$, is examined during 3-11 December (Figs. 7a,b). The results of 1-3and 7-9-day lead times for the $60-15-\mathrm{km}$ simulation capture the largest northerly wind signal occurring on 8 December. Moreover, the overall magnitude of coldsurge index is more consistent with observations in the $60-15-\mathrm{km}$ experiment (Fig. 7b) than in the $60-\mathrm{km}$ simulation (Fig. 7a).

The time series of areal-averaged synoptic (Fig. $6 \mathrm{~g}$, red rectangle) 925 -hPa vorticity between the 60 - and $60-$ $15-\mathrm{km}$ experiments are then compared (Figs. 7c,d). Although the $60-15-\mathrm{km}$ simulation seems to have a better representation of the cold surge (Figs. 7a,b), the synoptic vorticity in the SCS is comparable between the two experiments. Therefore, in a large-scale perspective, the outbreak of the cold surge and the vorticity associated with the BV are similar in both model configurations. Concerning convective development and organized precipitation, however, the simulated $\mathrm{BV}$ in the $60-15-\mathrm{km}$ simulation is better coupled with convection and may provide more valuable information for local weather forecasting.

\section{b. The simulation of a Kelvin wave, its interaction with trade wind, and the subsequent TC formation during 16-20 December}

This subsection examines the simulation of another important interaction event during 16-20 December (Fig. 1). As shown in Fig. 8, a weak cyclonic circulation associated with $\mathrm{KW} 2$ was located at around $0^{\circ}, 150^{\circ} \mathrm{E}$ on 16 December (Fig. 8a). On the same day, an equatorial Rossby wave disturbance was embedded in the shear line south to the trade winds and east of the KW2 (Fig. 8a) and slowly moved eastward. The convection of this eastward-moving $\mathrm{KW}$ on the equator then interacted with the westward-moving equatorial Rossby wave at around $5^{\circ} \mathrm{N}$ on 18 December (Figs. 8a,d). The interaction of the two waves resulted an enhanced circulation and triggered the formation of the MT4 in the area of $0^{\circ}-5^{\circ} \mathrm{N}, 140^{\circ}-150^{\circ} \mathrm{E}$ on 20 December (Fig. 8g; see also Fig. 1) and subsequently the cyclogenesis of TC Nock-ten.

The MPAS 60-km simulation (Fig. 8, center column) and $60-15-\mathrm{km}$ simulation (Fig. 8, right column) both 

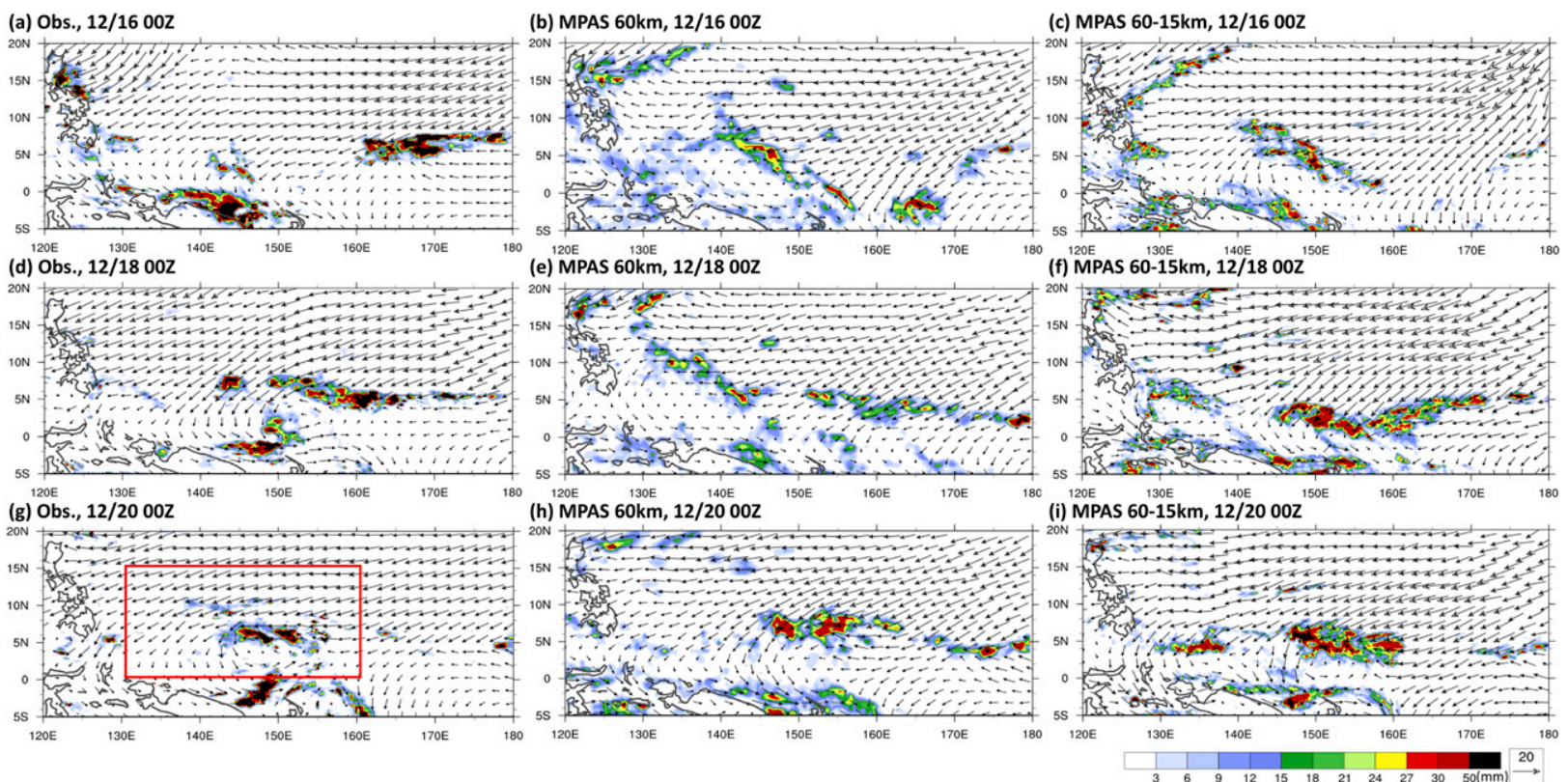

FIG. 8. (left) GPM 6-hourly rainfall and FNL 925-hPa winds and MPAS (center) 60- and (right) 60-15-km 6-hourly rainfall and 925-hPa winds at a lead time of 5 days at (a)-(c) 0000 UTC 16 Dec, (d)-(f) 0000 UTC 18 Dec, and (g)-(i) 0000 UTC 20 Dec.

overforecast the magnitude of the trade winds on 16 December, and the disturbance associated with the trade wind is located about $15^{\circ}$ west of the location in the observation (Fig. $8 \mathrm{a}, 5^{\circ} \mathrm{N}, 165^{\circ} \mathrm{E}$ ). Moreover, the organized convective feature associated with the KW2 is not properly simulated in the $60-\mathrm{km}$ simulation, while it is fairly well simulated in the $60-15-\mathrm{km}$ simulation. Therefore, the MPAS 60-15-km simulation has stronger precipitation and relatively compact cyclonic circulation at $5^{\circ} \mathrm{S}-5^{\circ} \mathrm{N}, 145^{\circ}-155^{\circ} \mathrm{E}$, where the interaction occurs between KW2 and MT4 during 18-20 December.

Figure 9 analyzes the frequency distribution of rain rates during 15 December to 20 December for GPM rainfall (Fig. 9, vertical bars), and the simulated rainfall ratios with respect to the GPM rain-rate distribution. The simulated ratios in Fig. 9 are the 4-7-day lead simulation by MPAS 60-km (blue line) and 4-6-day lead simulation by the MPAS $60-15-\mathrm{km}$ simulation (red

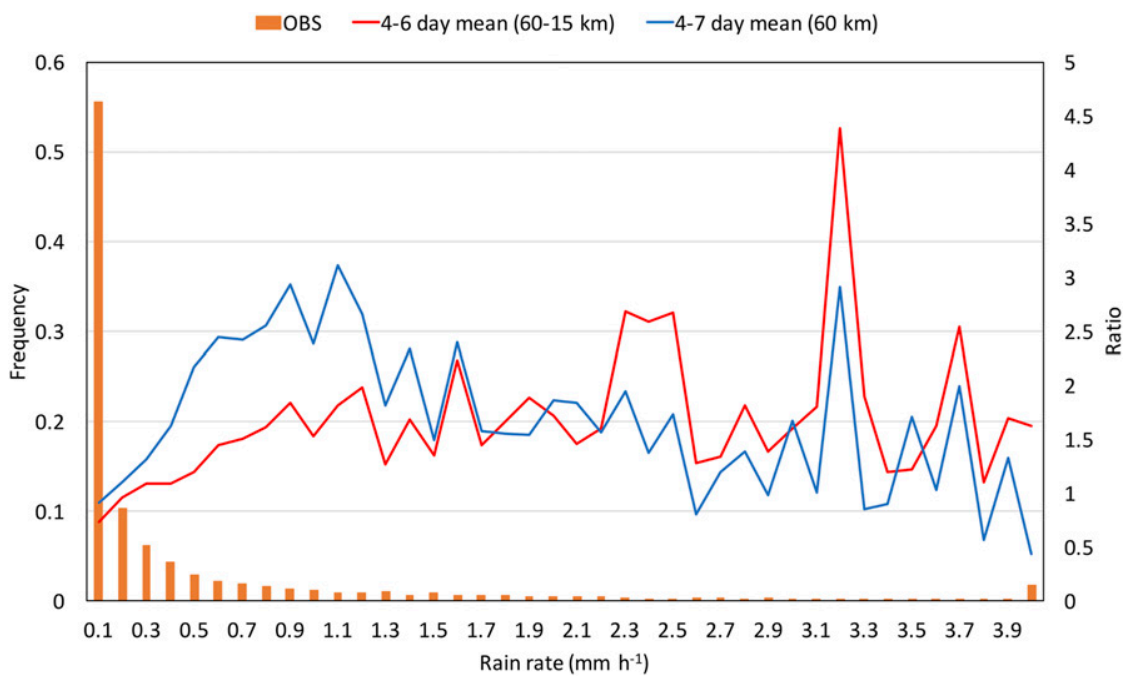

FIG. 9. Probability distribution frequency of rain rates during 15-20 Dec for GPM rainfall (bar, left $y$ axis) in the red box in Fig. 8g, and the ratios (right $y$ axis) with respect to the GPM rain-rate distribution for the MPAS 60-km 4-7-day-lead simulation (blue line) and MPAS 60-15-km 4-6-day-lead simulation (red line). 


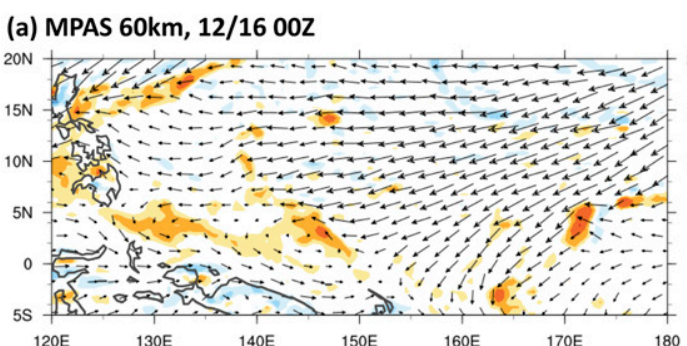

(b) MPAS 60-15km, 12/16 00Z
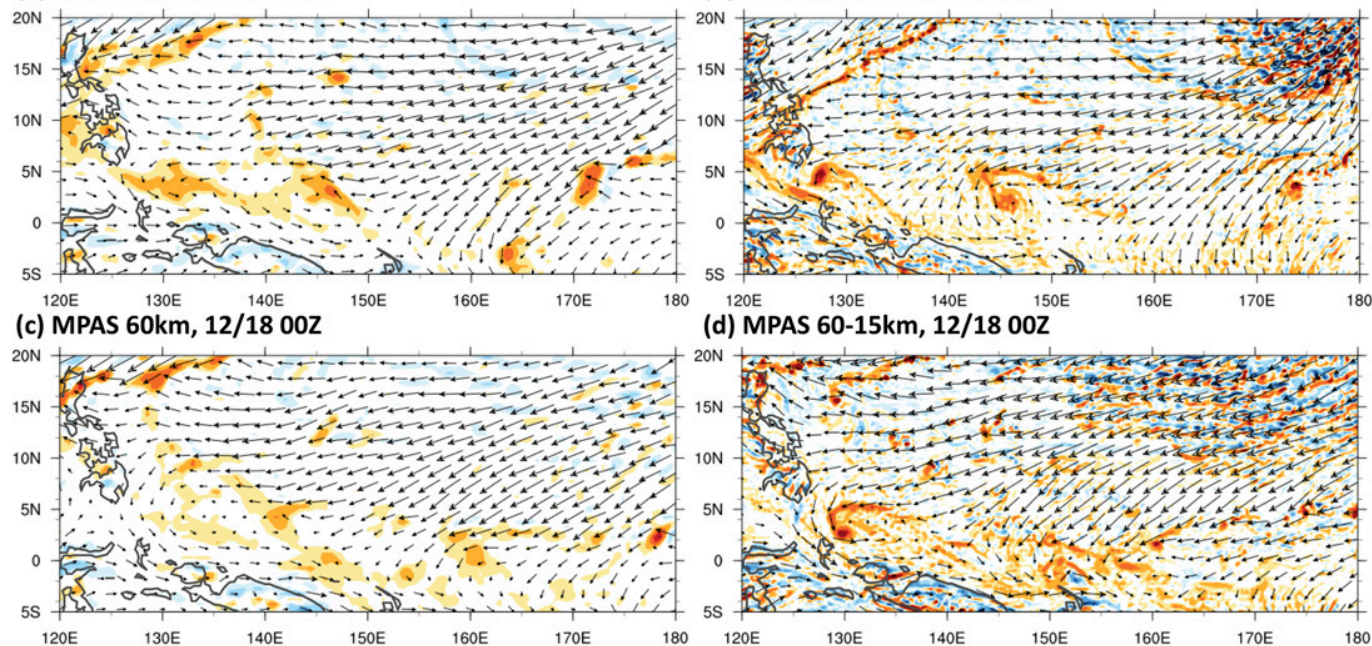

(d) MPAS $60-15 \mathrm{~km}, 12 / 1800 Z$
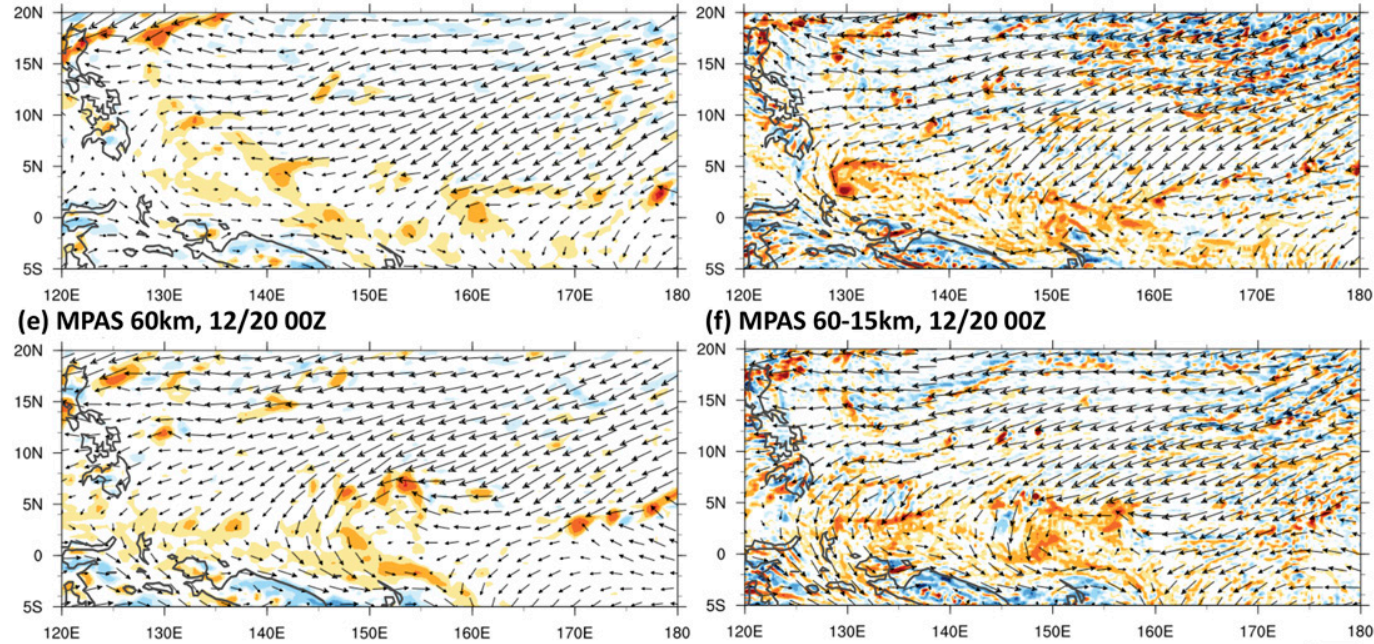

(f) MPAS $60-15 \mathrm{~km}, 12 / 2000 \mathrm{Z}$

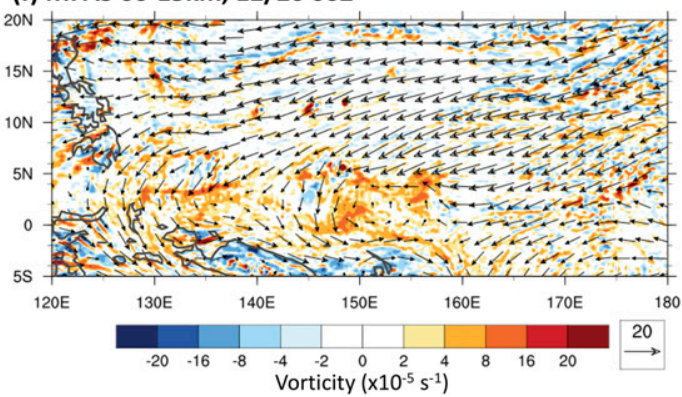

FIG. 10. MPAS (left) 60- and (right) 60-15-km simulated 925-hPa vorticity and winds at (a),(b) 0000 UTC 16 Dec, (c),(d) 0000 UTC 18 Dec, and (e),(f) 0000 UTC 20 Dec.

line). The rainfall frequency in the MPAS $60-15-\mathrm{km}$ simulation is generally smaller than that of the MPAS $60-\mathrm{km}$ simulation for rain rates smaller than $1.5 \mathrm{~mm} \mathrm{~h}^{-1}$. The rainfall frequency of both experiments is about the same for a rain rate in the range of $1.5-2.1 \mathrm{~mm} \mathrm{~h}^{-1}$, and the rainfall frequency of the MPAS $60-15-\mathrm{km}$ simulation is usually lager for a rain rate larger than $2.3 \mathrm{~mm} \mathrm{~h}^{-1}$. The ratio of the MPAS $60-15-\mathrm{km}$ simulation is about 1.5 times larger than the GPM rainfall for most of the rain-rate range. Figure 10 also shows the simulated vorticity evolution during 16-20 December. The simulated vorticity fields by the MPAS $60-15-\mathrm{km}$ simulation are obviously stronger and more coherent, especially at around $150^{\circ} \mathrm{E}$ near the equator, on 16 December, and $0^{\circ}-5^{\circ} \mathrm{N}, 140^{\circ}-150^{\circ} \mathrm{E}$ on 20 December. Overall, the MPAS 60-15-km run simulates the synoptic interaction events with stronger convection coupled with $\mathrm{KW}$ and MT waves.

\section{Summary and discussion}

As the scale interaction events between low-frequency flow (KWs, winter monsoon) and synoptic disturbances
(MTs, BV) over the SCS-MC play the dominant roles in the convective activity in December 2016, this study evaluates MPAS simulations of KW and its interactions with the BV and MTs. The goal of this study is to better understand the representation of convective processes in the tropical-subtropical environment in a global atmospheric model. There were two KWs initiated within the equatorial region near $90^{\circ} \mathrm{E}$ and propagated eastward to around $160^{\circ} \mathrm{E}$. North of the equator, four prominent convective disturbances propagated westward, including tropical cyclones associated with an ER wave and an MT wave. Moreover, a BV formed in the SCS. Note that these events interacted with the KWs, as they propagated westward. Two sets of hindcast experiments were conducted. The first one was with horizontal uniform $60-\mathrm{km}$-resolution mesh. The other set was with a $60-15-\mathrm{km}$ variable-resolution mesh that covers the SCS and western Pacific. We compare the $60-\mathrm{km}$ simulation with the $60-15-\mathrm{km}$ simulation in large-scale pattern correlations, and examine the synoptic convection structures to see if the finer convectivescale structure could feed back to large-scale simulation performance. 
The daily averaged correlation coefficients $R$ of simulated $P, \zeta$, and $\delta$ are analyzed for equatorial and offequatorial latitudinal bands. In general, the $60-15-\mathrm{km}$ experiment does not show significant improvement in $R$. The analysis of daily pattern correlations show that the spatial $R$ of rainfall are identical for 60 - and $60-15-\mathrm{km}$ simulations, but the $60-15-\mathrm{km}$ simulation usually has better performance in vorticity and divergence. The two sets of experiments of different resolutions show the capability of simulating the $\mathrm{KW}, \mathrm{ER}$, and MT wave signals and associated rainfall in December 2016. Increasing the resolution to $15 \mathrm{~km}$ does not result in an improved simulation of average wave structures in latitudinal band, but better resolves convective synoptic circulations (vorticity and divergence fields).

Two scale-interaction events are further examined during December 2016 to evaluate the model capability of simulating synoptic convection. One is the evolution of the BV during 6-10 December. The other is the interaction between KW2 and ER, and the MT waves related to TC Nock-ten. In the first case, compared with the results of $60-\mathrm{km}$ experiment, the $60-15-\mathrm{km}$ experiment better simulates the occurrence of cold surges, while the simulated synoptic-scale vorticity in SCS is comparable between the two experiments. However, the $60-15-\mathrm{km}$ simulated convection near the BV is stronger and more organized due to the cyclonic circulation. In the second case, the $60-15-\mathrm{km}$ experiment also simulates stronger precipitation accompanied with a stronger and compact vorticity structure in the area where KW2 interacts with the MT4 waves. In both synoptic events, $60-15-\mathrm{km}$ resolution better simulates the convection-coupled structures caused by the interaction between KW and MT waves.

In summary, MPAS with a $60-15-\mathrm{km}$ mesh better simulates the convection and vorticity structures than with a $60-\mathrm{km}$ mesh. However, the equatorial wave structures and associated large-scale flow did not show much difference. This may explain why the analysis of large-scale precipitation and vorticity is similar in the two interaction event cases. A more suitable representation of cumulus processes for the variable-resolution experiment is needed to improve the simulation of convection-coupled KW and MT waves. Furthermore, the $15-\mathrm{km}$ resolution appears to have limitations in simulating mesoscale rainfall and topography in our experiments. Increasing the resolution to resolve cumulus convection is expected to result in better simulation of wave interaction cases. In addition, we have tested the experiments with nudging SST toward daily observed values (not shown). The results show that the simulations are not sensitive in the first 7 days, and only have slightly influence for 7-10-day simulations. More cases in the SCS-MC area will be studied in the future, including examination of the improvement due to coupled ocean models to hindcast results.

Acknowledgments. This work is supported by Ministry of Science and Technology of Taiwan, under Grants MOST105-2119-M-002-025 and MOST106-2111-M-002003-MY2. We thank Taiwan Typhoon and Flood Research Institute for providing part of the MPAS data.

\section{REFERENCES}

Birch, C. E., M. J. Roberts, L. Garcia-Carreras, D. Ackerley, M. J. Reeder, A. P. Lock, and R. Schiemann, 2015: Sea breeze dynamics and convection initiation: The influence of convective parameterization in weather and climate model biases. J. Climate, 28, 8093-8108, https://doi.org/10.1175/JCLI-D14-00850.1.

Chang, C.-P., C.-H. Liu, and H.-C. Kuo, 2003: Typhoon Vamei: An equatorial tropical cyclone formation. Geophys. Res. Lett., 30, 1150, https://doi.org/10.1029/2002GL016365.

, P. A. Harr, and H.-J. Chen, 2005: Synoptic disturbances over the equatorial South China Sea and western Maritime Continent during boreal winter. Mon. Wea. Rev., 133, 489503, https://doi.org/10.1175/MWR-2868.1.

_ Z Z. Wang, and H. Hendon, 2006: The Asian winter monsoon. The Asian Monsoon, B. Wang, Ed., Praxis, 89-127.

, M. Lu, and H. Lim, 2016: Monsoon convection in the Maritime Continent: Interaction of large-scale motion and complex terrain. Multiscale Convection-Coupled Systems in the Tropics: A Tribute to Dr. Michio Yanai, Meteor. Monogr., No. 56, Amer. Meteor. Soc., https://doi.org/10.1175/AMSMONOGRAPHSD-15-0011.1.

Cheang, B. K., 1977: Synoptic features and structures of some equatorial vortices over the South China Sea in the Malaysian region during the winter monsoon of December 1973. Pure Appl. Geophys., 115, 1303-1333, https://doi.org/10.1007/BF00874411.

Chen, W.-T., S.-P. Hsu, Y.-H. Tsai, and C.-H. Sui, 2019: The influences of convectively coupled Kelvin waves on multiscale rainfall variability over the South China Sea and Maritime Continent in December 2016. J. Climate, 32, 6977-6993, https://doi.org/10.1175/JCLI-D-18-0471.1.

Davis, C. A., D. A. Ahijevych, W. Wang, and W. C. Skamarock, 2016: Evaluating medium-range tropical cyclone forecasts in uniform- and variable-resolution global models. Mon. Wea. Rev., 144, 4141-4160, https://doi.org/10.1175/MWR-D-160021.1.

Dunkerton, T. J., and F. X. Crum, 1995: Eastward propagating 2- to 15 -day equatorial convection and its relation to the tropical intraseasonal oscillation. J. Geophys. Res., 100, 25 781-25 790, https://doi.org/10.1029/95JD02678.

Frank, W. M., and P. E. Roundy, 2006: The role of tropical waves in tropical cyclogenesis. Mon. Wea. Rev., 134, 2397-2417, https:// doi.org/10.1175/MWR3204.1.

Gottschalck, J., P. E. Roundy, C. J. Schreck, A. Vintzileos, and C. Zhang, 2013: Large-scale atmospheric and oceanic conditions during the 2011-2012 DYNAMO field campaign. Mon. Wea. Rev., 141, 4173-4196, https://doi.org/10.1175/MWR-D13-00022.1.

Hagos, S., R. Leung, S. A. Rauscher, and T. Ringler, 2013: Error characteristics of two grid refinement approaches in aquaplanet 
simulations: MPAS-A and WRF. Mon. Wea. Rev., 141, 30223036, https://doi.org/10.1175/MWR-D-12-00338.1.

Hong, S.-Y., and J. O. J. Lim, 2006: The WRF single-moment 6-class microphysics scheme (WSM6). J. Korean Meteor. Soc., 42, 129-151.

—, Y. Noh, and J. Dudhia, 2006: A new vertical diffusion package with an explicit treatment of entrainment processes. Mon. Wea. Rev., 134, 2318-2341, https://doi.org/10.1175/ MWR3199.1.

Huang, C.-Y., Y. Zhang, W. C. Skamarock, and L.-H. Hsu, 2017: Influences of large-scale flow variations on the track evolution of Typhoons Morakot (2009) and Megi (2010): Simulations with a global variable-resolution model. Mon. Wea. Rev., 145 , 1691-1716, https://doi.org/10.1175/MWR-D-16-0363.1.

Huffman, G. J., and Coauthors, 2017a: NASA Global Precipitation Measurement (GPM) Integrated Multi-satellitE Retrievals for GPM (IMERG). Algorithm Theoretical Basis Doc., version 5.1, 34 pp., https://pmm.nasa.gov/sites/default/files/ document_files/IMERG_ATBD_V5.1b.pdf.

, D. T. Bolvin, and E. J. Nelkin, 2017b: Integrated MultisatellitE Retrievals for GPM (IMERG) technical documentation. NASA Tech. Doc., 54 pp., https://pmm.nasa.gov/sites/ default/files/document_files/IMERG_technical_doc_3_22 17.pdf.

Iacono, M. J., J. S. Delamere, E. J. Mlawer, M. W. Shephard, S. A. Clough, and W. D. Collins, 2008: Radiative forcing by longlived greenhouse gases: Calculations with the AER radiative transfer models. J. Geophys. Res., 113, D13103, https://doi.org/ 10.1029/2008JD009944.

Johnson, R. H., and R. A. Houze Jr., 1987: Precipitating cloud systems of the Asian monsoon. Monsoon Meteorology, C.-P. Chang and T. N. Krishnamurti, Eds., Oxford University Press, 298-353.

Klemp, J. B., 2011: A terrain-following coordinate with smoothed coordinate surfaces. Mon. Wea. Rev., 139, 2163-2169, https:// doi.org/10.1175/MWR-D-10-05046.1.

Lau, K. M., and C. P. Chang, 1987: Planetary scale aspects of winter monsoon and teleconnections. Monsoon Meteorology, C. P. Chang and T. N. Krishnamurti, Eds., Oxford University Press, 161-202.

Lindzen, R. S., 1967: Planetary waves on beta planes. Mon. Wea. Rev., 95, 441-451, https://doi.org/10.1175/1520-0493(1967) 095<0441:PWOBP $>2.3 . \mathrm{CO} ; 2$.

Madden, R. A., and P. R. Julian, 1972: Description of global-scale circulation cells in the tropics with a 40-50 day period. J. Atmos. Sci., 29, 1109-1123, https://doi.org/10.1175/15200469(1972)029<1109:DOGSCC > 2.0.CO;2.

Majda, A. J., and B. Khouider, 2004: A model for convectively coupled tropical waves: Nonlinearity, rotation, and comparison with observations. J. Atmos. Sci., 61, 2188-2205, https://doi.org/10.1175/1520-0469(2004)061<2188:AMFCCT> 2.0.CO;2.

Mapes, B., S. Tulich, J. Lin, and P. Zuidema, 2006: The mesoscale convection life cycle: Building block or prototype for largescale tropical waves? Dyn. Atmos. Oceans, 42, 3-29, https:// doi.org/10.1016/j.dynatmoce.2006.03.003.

Matsuno, T., 1966: Quasi-geostrophic motions in the equatorial area. J. Meteor. Soc. Japan, 44, 25-43, https://doi.org/10.2151/ jmsj1965.44.1_25.

National Centers for Environmental Prediction/National Weather Service/NOAA/U.S. Department of Commerce, 2000: NCEP FNL operational model global tropospheric analyses, continuing from July 1999. Research Data Archive at the National
Center for Atmospheric Research, Computational and Information Systems Laboratory, accessed 1 January 2017, https://doi.org/10.5065/D6M043C6.

—, 2007: NCEP Global Forecast System (GFS) analyses and forecasts. Research Data Archive at the National Center for Atmospheric Research, Computational and Information Systems Laboratory, accessed 24 November 2016, https:// doi.org/10.5065/D65Q4TSG.

Park, S.-H., J. B. Klemp, and W. C. Skamarock, 2014: A comparison of mesh refinement in the global MPAS-A and WRF models. Mon. Wea. Rev., 142, 3614-3634, https://doi.org/ 10.1175/MWR-D-14-00004.1.

Pilon, R., C. Zhang, and J. Dudhia, 2016: Roles of deep and shallow convection and microphysics in the MJO simulated by the Model for Prediction Across Scales. J. Geophys. Res. Atmos., 121, 10 575-10 600, https://doi.org/10.1002/ 2015JD024697.

Ramage, C. S., 1968: Role of a tropical "maritime continent" in the atmospheric circulation. Mon. Wea. Rev., 96, 365-370, https://doi.org/10.1175/1520-0493(1968)096<0365:ROATMC $>$ 2.0.CO;2.

Roundy, P. E., and W. M. Frank, 2004: A climatology of waves in the equatorial region. J. Atmos. Sci., 61, 2105-2132, https://doi.org/10.1175/1520-0469(2004)061<2105:ACOWIT> 2.0.CO;2.

Schreck, C. J., 2015: Kelvin waves and tropical cyclogenesis: A global survey. Mon. Wea. Rev., 143, 3996-4011, https://doi.org/ 10.1175/MWR-D-15-0111.1.

- and J. Molinari, 2011: Tropical cyclogenesis associated with Kelvin waves and the Madden-Julian oscillation. Mon. Wea Rev., 139, 2723-2734, https://doi.org/10.1175/MWR-D-1005060.1

Skamarock, W. C., J. B. Klemp, M. G. Duda, L. D. Fowler, S.-H Park, and T. D. Ringler, 2012: A multiscale nonhydrostatic atmospheric model using centroidal Voronoi tesselations and C-grid staggering. Mon. Wea. Rev., 140, 3090-3105, https:// doi.org/10.1175/MWR-D-11-00215.1.

Takayabu, Y. N., and T. Nitta, 1993: 3-5 day-period disturbances coupled with convection over the tropical Pacific Ocean. J. Meteor. Soc. Japan, 71, 221-246, https://doi.org/10.2151/ jmsj1965.71.2_221.

Trilaksono, N. J., S. Otsuka, and S. Yoden, 2012: A time-lagged ensemble simulation on the modulation of precipitation over West Java in January-February 2007. Mon. Wea. Rev., 140, 601-616, https://doi.org/10.1175/MWR-D-11-00094.1.

Ventrice, M. J., C. D. Thorncroft, and M. A. Janiga, 2012: Atlantic tropical cyclogenesis: A three-way interaction between an African easterly wave, diurnally varying convection, and a convectively coupled atmospheric Kelvin wave. Mon. Wea Rev., 140, 1108-1124, https://doi.org/10.1175/MWR-D-1100122.1

Vitart, F., 2014: Evolution of ECMWF sub-seasonal forecast skill scores. Quart. J. Roy. Meteor. Soc., 140, 1889-1899, https:// doi.org/10.1002/qj.2256.

- A. W. Robertson, and S2S Steering Group, 2015: Subseasonal to seasonal prediction: Linking weather and climate. Seamless Prediction of the earth system: From minutes to months, WMO1156, WMO, 385-401.

Wang, H., and R. Fu, 2007: The influence of Amazon rainfall on the Atlantic ITCZ through convectively coupled Kelvin waves. J. Climate, 20, 1188-1201, https://doi.org/10.1175/JCLI4061.1.

Wheeler, M. C., and G. N. Kiladis, 1999: Convectively coupled equatorial waves: Analysis of clouds and temperature in the 
wavenumber-frequency domain. J. Atmos. Sci., 56, 374-399, https:// doi.org/10.1175/1520-0469(1999)056<0374:CCEWAO>2.0.CO;2.

_, — , and P. J. Webster, 2000: Large-scale dynamical fields associated with convectively coupled Kelvin waves. J. Atmos. Sci., 57, 613-640, https://doi.org/10.1175/1520-0469(2000)057 $<0613$ :LSDFAW $>2.0 . \mathrm{CO} ; 2$.

White, C. J., and Coauthors, 2017: Potential applications of subseasonal-to-seasonal (S2S) predictions. Meteor. Appl., 24, 315-325, https://doi.org/10.1002/met.1654.

Wu, P., M. Hara, H. Fudeyasu, M. D. Yamanaka, J. Matsumoto, F. Syamsudin, R. Sulistyowati, and Y. S. Djajadihardja, 2007: The impact of trans-equatorial monsoon flow on the formation of repeated torrential rains over Java island. SOLA, 3, 93-96, https://doi.org/10.2151/SOLA.2007-024.
Yanase, W., M. Satoh, H. Yamada, K. Yasunaga, and Q. Moteki, 2010: Continual influences of tropical waves on the genesis and rapid intensification of Typhoon Durian (2006). Geophys. Res. Lett., 37, L08809, https://doi.org/10.1029/ 2010 GL042516.

Yoneyama, K., C. Zhang, and C. N. Long, 2013: Tracking pulses of the Madden-Julian oscillation. Bull. Amer. Meteor. Soc., 94, 1871-1891, https://doi.org/10.1175/BAMS-D-1200157.1.

Zhang, C., Y. Wang, and K. Hamilton, 2011: Improved representation of boundary layer clouds over the southeast Pacific in ARW-WRF using a modified Tiedtke cumulus parameterization scheme. Mon. Wea. Rev., 139, 3489-3513, https:// doi.org/10.1175/MWR-D-10-05091.1. 